\title{
Kinematic Analysis of the Reconstruction Error of A Calibration Volume for 3d Analysis in Swimming
}

\author{
S. Brandão, P. Figueiredo, P. Gonçalves, J.P. Vilas-Boas and R.J. Fernandes*
}

University of Porto, Faculty of Sport, Cifi2d, Porto, Portugal

\begin{abstract}
The purpose of this study was to assess the accuracy and reliability of the three-dimensional reconstruction above and below water - of a calibration volume for three-dimensional analysis in swimming. The calibration volume $(3 \times 3 \times 3 \mathrm{~m})$ was placed in a $25 \mathrm{~m} \times 12.5 \mathrm{~m} \times 2 \mathrm{~m}$ swimming pool and was recorded simultaneously by 4 under and 2 above water synchronized cameras. To assess the number of control points required to maximise the accuracy of threedimensional coordinate reconstruction, 12 markers in the calibrated space were digitised over 10 fields for each underwater and above water camera views. Seven series of 12 markers, using 8, 12, 16, 20, 24, 28 and 30 control points were digitised. Direct linear transformation methods were used to estimate the marker locations on the volume. Comparison among different numbers of control points showed that the set of 20 (underwater) and 16 (above water) points produced the most accurate results. The average root mean square errors were (x, y and z, respectively): (i) $4.85 \mathrm{~mm}, 2.52 \mathrm{~mm}$ and $7.43 \mathrm{~mm}$ (set of 20 digitised underwater points) and (ii) $4.11 \mathrm{~mm}, 5.69 \mathrm{~mm}$ and $3.90 \mathrm{~mm}$ (set of 16 digitised above water points). The standard deviation in underwater cameras was $1.22 \mathrm{~mm}, 0.33 \mathrm{~mm}$ and $3.47 \mathrm{~mm}$, and $1.57 \mathrm{~mm}, 2.63 \mathrm{~mm}$ and $2.35 \mathrm{~mm}$ for above water cameras (for $\mathrm{x}, \mathrm{y}$ and $\mathrm{z}$, respectively). The calibration volume was found to have high accuracy and reliability.
\end{abstract}

Keywords: Above water, accuracy, biomechanics, reliability, three-dimensional, underwater.

\section{INTRODUCTION}

In multiplanar activities such as swimming, kinematical analysis should be three-dimensional (3D). However, most studies in swimming were limited to two-dimensional (2D) analysis techniques, which imply higher number of errors, once disregards especial characteristics of movements, particularly of the limbs. In 3D analysis the most popular technique used for the transformation of the 2D image coordinates into 3D space coordinates is the direct linear transformation procedure (DLT) [1]. With the DLT technique an appropriate number of points with known 3D coordinates (control points) on a calibration volume are used for the calibration of the recording space. In this procedure, the number and distribution [1] of the control points, as well as the size of calibration volume [2] affect reconstruction accuracy. Psycharakis et al. [3] showed improvement in the calibration accuracy when the number of control points were increased from 10 to 20 , using a calibration volume of $6.75 \mathrm{~m}^{3}$, while Gourgoulis et al. [4] using measurements carried out in two different recording conditions: (i) out of the water and (ii) in the water, found larger reconstruction errors in water compared to above water conditions, whatever the size of the calibration volume. Moreover, Chen et al. [1] and Kwon [5] pointed out that reconstruction accuracy should be assessed using a number of validation points that did not serve as control points since the DLT parameters are optimised for the reconstruction of the control points.

*Address correspondence to this author at the Faculty of Sport, Porto University, Portugal; Tel: +351 225074763; E-mail: Ricfer@fade.up.pt
The purpose of this study was to assess the accuracy of the $3 \mathrm{D}$ reconstruction, above and below water of a calibration volume for $3 \mathrm{D}$ analysis in swimming.

\section{METHODS}

The calibration volume $(3 \times 3 \times 3 \mathrm{~m})$ was placed into a $25 \mathrm{~m}$ x $12.5 \mathrm{~m}$ x $2 \mathrm{~m}$ swimming pool and recorded simultaneously by 4 under and 2 above water cameras (Sony ${ }^{\circledR}$ DCRHC42E). The cameras were at depths varying from 1.0 to $1.5 \mathrm{~m}$ below the water surface to avoid errors due to the camera axes being in the same planes as the reference planes of the volume. The cameras above water were varying from 3.0 to $3.5 \mathrm{~m}$ above water surface. The angle between the axes of the two above water camera axes was approximately $120^{\circ}$, while the angles between axes of adjacent below water camera axes varied from approximately $75^{\circ}$ to $110^{\circ}$ The following procedure was applied to assess the number of control points required to maximise the accuracy of $3 \mathrm{D}$ coordinate reconstruction for the below water calibration: 12 markers in the calibrated space were digitised over 10 fields for each underwater and above water camera viewers. Seven series of digitising were performed for this set of 12 markers, using 8 , $12,16,20,24,28$ and 30 control points respectively. To avoid overestimating accuracy the 12 markers selected for these comparisons were not included in any set of calibration points [6]. The 3D coordinates were obtained using the DLT procedure [7], and the associated error with RMS. The differences between the obtained and the known values were calculated for the $\mathrm{x}, \mathrm{y}$, and $\mathrm{z}$ coordinates of each point for each of the 10 video fields. To obtain an estimate of reliability, the same operator (in order to avoid any inter-operator 
errors) repeated the procedure 10 times. The reliability measure was considered to be the standard deviation across all digitisations of the marker.

\section{RESULTS}

In Table $\mathbf{1}$ it is presented the mean difference and the mean RMS errors for the $\mathrm{x}, \mathrm{y}$ and $\mathrm{z}$ coordinates, for different numbers of control points for the underwater cameras. The accuracy increased as the number of control points increased from 8 to 16 , and from 20 to 28 . A further increase to 30 points did not improve the accuracy of the measurements.

In Table $\mathbf{2}$ it is possible to observe the mean difference and the mean RMS errors for the $\mathrm{x}, \mathrm{y}$ and $\mathrm{z}$ coordinates, for different numbers of control points in above water cameras, where the accuracy increased as the number of control points increased from 24 to 30 .

For the calculations performed following the selection of a set of 12 control points, the average RMS errors for the set of 20 digitised points underwater, was $4.85 \mathrm{~mm}, 2.52 \mathrm{~mm}$ and $7.43 \mathrm{~mm}$ for the $\mathrm{x}, \mathrm{y}$ and $\mathrm{z}$ directions, respectively, representing $0.16 \%, 0.08 \%$ and $0.25 \%$ of the calibrated space. For the set of 16 digitised points above water, the average RMS errors was $4.11 \mathrm{~mm}, 5.69 \mathrm{~mm}$ and $3.90 \mathrm{~mm}$ for the $\mathrm{x}, \mathrm{y}$ and $\mathrm{z}$ directions respectively, representing $0.14 \%, 0.19 \%$ and $0.13 \%$ of the calibrated space. These values were lower than the values found for all the sets of different numbers of control points described above, both under and above water. The standard deviation in underwater cameras was $1.22 \mathrm{~mm}$, $0.33 \mathrm{~mm}$ and $3.47 \mathrm{~mm}$ for the $\mathrm{x}, \mathrm{y}$ and $\mathrm{z}$ directions respectively. In the above water cameras the values are $1.57 \mathrm{~mm}$, $2.63 \mathrm{~mm}$ and $2.35 \mathrm{~mm}$.

\section{DISCUSSION}

Considering the calibration volume used, the errors were similar or even lower than those reported in other studies. Psycharakis et al. [3] reported the mean difference for the set of 30 digitised points was $3.3 \mathrm{~mm}, 2.6 \mathrm{~mm}$ and $4.0 \mathrm{~mm}$, for the $\mathrm{x}, \mathrm{y}$ and $\mathrm{z}$ axes respectively. The average RMS error for these points was $3.9 \mathrm{~mm}, 3.8 \mathrm{~mm}$ and $4.8 \mathrm{~mm}$ for the $\mathrm{x}, \mathrm{y}$ and $\mathrm{z}$ directions respectively. Gourgoulis et al. [4] using two calibration volumes, one smaller and other larger, were the RMS values were respectively $1.61 \mathrm{~mm}$ and $2.35 \mathrm{~mm}$ in the transverse axis, $2.99 \mathrm{~mm}$ and $4.64 \mathrm{~mm}$ in the longitudinal axis and $2.83 \mathrm{~mm}$ and $2.59 \mathrm{~mm}$ in the vertical axis. Payton and Bartlett [8] reported corresponding values of $2.3 \mathrm{~mm}, 3.3 \mathrm{~mm}$ and $2.9 \mathrm{~mm}$ while Payton et al. [9] reported mean errors of

Table 1. Mean Difference and Mean RMS Errors for Underwater Cameras in the $x, y$ and $z$ Axis

\begin{tabular}{|c|c|c|c|c|c|c|}
\hline \multicolumn{7}{|c|}{ Underwater Cameras } \\
\hline \multirow{2}{*}{ Number of Control Points } & \multicolumn{3}{|c|}{ RMS (mm) } & \multicolumn{3}{|c|}{ Mean Difference (mm) } \\
\hline & $\mathbf{x}$ & $\mathbf{y}$ & $\mathbf{z}$ & $\mathbf{x}$ & $\mathbf{y}$ & $\mathbf{z}$ \\
\hline 8 & 6.38 & 2.93 & 3.52 & 0.09 & 0.41 & 0.12 \\
\hline 12 & 5.93 & 3.31 & 4.43 & 0.35 & 0.11 & 0.19 \\
\hline 16 & 4.88 & 2.93 & 8.09 & 0.24 & 0.09 & 0.65 \\
\hline 20 & 4.85 & 2.52 & 7.43 & 0.24 & 0.06 & 0.55 \\
\hline 24 & 4.35 & 2.38 & 9.71 & 0.19 & 0.06 & 0.94 \\
\hline 28 & 3.39 & 2.52 & 13.9 & 0.11 & 0.06 & 1.93 \\
\hline 30 & 3.05 & 2.52 & 9.13 & 0.09 & 0.06 & 0.83 \\
\hline
\end{tabular}

Table 2. Mean Difference and Mean RMS Errors for the Above Water Cameras in the $x, y$ and $z$ Axis

\begin{tabular}{|c|c|c|c|c|c|c|}
\hline \multicolumn{7}{|c|}{ Above Water Cameras } \\
\hline \multirow{2}{*}{ Number of Control Points } & \multicolumn{3}{|c|}{ RMS (mm) } & \multicolumn{3}{|c|}{ Mean Difference (mm) } \\
\hline & $\mathbf{x}$ & $\mathbf{y}$ & $\mathbf{z}$ & $\mathbf{x}$ & $\mathbf{y}$ & $\mathbf{z}$ \\
\hline 8 & 1.26 & 1.26 & 6.7 & 0.02 & 0.02 & 0.08 \\
\hline 12 & 2.18 & 8.32 & 2.85 & 4.76 & 0.69 & 0.12 \\
\hline 16 & 4.11 & 5.69 & 3.9 & 0.17 & 0.00 & 0.78 \\
\hline 20 & 4.11 & 5.69 & 4.34 & 0.17 & 0.00 & 0.78 \\
\hline 24 & 4.11 & 3.82 & 9.87 & 0.17 & 0.15 & 0.06 \\
\hline 28 & 1.65 & 2.75 & 4.81 & 0.00 & 0.08 & 0.00 \\
\hline 30 & 0.33 & 1.17 & 4.25 & 0.29 & 0.00 & 0.53 \\
\hline
\end{tabular}


1.5 to $3.1 \mathrm{~mm}$ for a $1.1 \mathrm{~m}^{3}$ volume (representing $0.2 \%$, of the calibrated space for each direction). Using a similar volume in a study of the golf swing, Coleman and Rankin [10] reported RMS errors of 5.1 to $9.8 \mathrm{~mm}$ (representing $0.4 \%$, $0.5 \%$ and $0.3 \%$ of the calibrated space, for the $\mathrm{x}, \mathrm{y}$ and $\mathrm{z}$ directions respectively). The reliabilities were lower when compared with Psycharakis' study [3], where the reliabilities indicated by repeated digitisations of one marker were \pm 0.4 $\mathrm{mm}, \pm 0.5 \mathrm{~mm}$ and $\pm 0.4 \mathrm{~mm}$, for the $\mathrm{X}, \mathrm{Y}$ and $\mathrm{Z}$ axes respectively.

\section{ACKNOWLEDGEMENT}

This study was supported by grant: PTDC/DES/101224/ 2008.

\section{REFERENCES}

[1] Chen L, Armstrong CW, Raftopoulos DD. An investigation on the accuracy of three-dimensional space reconstruction using the direct linear transformation technique. J Biomech 1994; 27: 493-500.

[2] Lam TC, Frank CB, Shrive NG. Calibration characteristics of a video dimension analyser (VDA) system. J Biomech1992; 25: $1227-31$.
[3] Psycharakis S, Sanders R, Mill F. A calibration frame for 3D swimming analysis. In: Wang Q, Ed. Proceedings of the XXIII International Symposium on Biomechanics in Sports 2005, Beijing China 2005; pp. 901-4.

[4] Gourgoulis V, Aggeloussis N, Kasimatis P, Vezos N, Boli A, Mavromatis G. Reconstruction accuracy in underwater threedimensional kinematic analysis. J Sci Med Sport 2008; 11 (2): 90-5.

[5] Kwon YH. Object plane deformation due to refraction in twodimentional underwater motion analysis. J Appl Biomech 1999; 15: 396-403.

[6] Challis JH, Kerwin DG. Accuracy assessment and control point configuration when using the DLT for photogrammetry. J Biomech 1992; 25 (9): 1053-8.

[7] Abdel-Aziz YI, Karara HM. Direct linear transformation from comparator coordinates into object space coordinates in close range photogrammetry. In: Proceedings of the American Society of Photogrammetry Symposium on Close Range Photogrammetry; Falls Church, American Society of Photogrammetry 1971; pp 1-18.

[8] Payton CJ, Bartlett RM. Estimating propulsive forces in swimming from three-dimensional kinematic data. J Sports Sci 1995; 13(6): 447-54.

[9] Payton C, Baltzopoulos V, Bartlett R. Contributions of rotations of the trunk and upper extremity to hand velocity during front crawl swimming. J Appl Biomech 2002; 18(3): 243-56.

[10] Coleman SG, Rankin AJ. A three-dimensional examination of the planar nature of the golf swing. J Sports Sci 2005; 23 (3): 227-34.

(C) Brandão et al.; Licensee Bentham Open.

This is an open access article licensed under the terms of the Creative Commons Attribution Non-Commercial License. (http://creativecommons.org/licenses/by-nc/3.0/) which permits unrestricted, non-commercial use, distribution and reproduction in any medium, provided the work is properly cited. 